\title{
Do Historical Changes in Parent-Child Relationships Explain Increases in Youth Conduct Problems?
}

\author{
Stephan Collishaw • Frances Gardner • \\ Barbara Maughan • Jacqueline Scott • Andrew Pickles
}

(C) Springer Science+Business Media, LLC 2011

\begin{abstract}
The coincidence of historical trends in youth antisocial behavior and change in family demographics has led to speculation of a causal link, possibly mediated by declining quality of parenting and parent-child relationships. No study to date has directly assessed whether and how parenting and parent-child relationships have changed. Two national samples of English adolescents aged 16-17 years in 1986 ( $N=4,524$ adolescents, 7,120 parents) and $2006(N=$ 716 adolescents, 734 parents) were compared using identical questionnaire assessments. Youth-reported parental monitor-
\end{abstract}

This research was supported by a Nuffield Foundation grant to FG, BM, SC and JS, and by a Nuffield Foundation New Career Development Fellowship to SC and AP. BM is supported by the Medical Research Council. SC is supported by the Waterloo Foundation. We are grateful to Ann Hagell for many helpful suggestions, the UK data archive for providing access to the 1970 British Cohort Study, the UK Department of Health for allowing us to re-contact participants of the Health Surveys for England, and to the National Centre for Social Research for undertaking the 2006 fieldwork.

Electronic supplementary material The online version of this article (doi:10.1007/s10802-011-9543-1) contains supplementary material, which is available to authorized users.

\section{S. Collishaw $(\bowtie)$}

Child and Adolescent Psychiatry Section and MRC Centre

for Neuropsychiatric Genetic and Genomics,

Department of Psychological Medicine and Neurology,

Cardiff University School of Medicine, Heath,

4th Floor,

Cardiff CF14 4XN, UK

e-mail: collishaws@cardiff.ac.uk

F. Gardner

Department of Social Policy and Social Work,

University of Oxford,

Oxford, UK ing, expectations, and parent-child quality time increased between 1986 and 2006. Ratings of parental interest did not change. Parenting differences between affluent and disadvantaged families narrowed over time. There was thus little evidence of a decline in quality of parenting for the population as a whole or for disadvantaged subgroups. Parent-reported youth conduct problems showed a modest increase between 1986 and 2006. Findings suggested that the increase in youth conduct problems was largely unrelated to observed change in parent-child relationships.
B. Maughan

MRC Social Genetic and Developmental Psychiatry Centre,

Institute of Psychiatry, Kings College London,

London, UK

J. Scott

Department of Sociology, University of Cambridge,

Cambridge, UK

A. Pickles

Department of Biostatistics, Institute of Psychiatry,

Kings College London,

London, UK 
Keywords Time trends $\cdot$ Parenting $\cdot$ Adolescent $\cdot$ Antisocial behavior

The second half of the 20th century saw substantial increases in adolescent antisocial behavior in many Western countries, including the US and UK (Achenbach et al. 2003; Collishaw et al. 2004; Maughan et al. 2005; Rutter and Smith 1995). Over the same period there were also dramatic changes in family composition (increased parental separation, fewer marriages, more single parent and step parent households, smaller families), major changes in the working lives of parents (more mothers working from earlier child ages, more dual earner families), and long term increases in child poverty and household income inequality (Amato and Booth 2000; Fomby and Cherlin 2007; Halsey and Webb 2000; Hoynes et al. 2006; Scott et al. 2004). Consequences of these historical shifts for children's outcomes are poorly understood, in part because of the difficulties inherent in drawing conclusions solely on the basis of population-level differences (Robinson 1950; Rutter and Smith 1995). Nevertheless, many commentators have concluded that macro-level family changes are likely to have made a substantial contribution to changes in rates of conduct problems (Ambert 2007; Gottfredson and Hirschi 1990; Wardle 2007). To date, however, there have been few empirical tests of this view, and one recent comparison of three UK national cohorts assessed in the 1970 s, 80s and 90s found that rising rates of adolescent antisocial behavior over time were only very modestly explained by concurrent changes in family type and socioeconomic conditions (Collishaw et al. 2007) even though within each cohort, parent separation and poverty were consistent correlates of poorer child outcomes.

One solution to this apparent puzzle lies with a consideration of how family-level factors such as poverty and family type influence children's development. There is now good evidence that proximal indicators of the dynamics of family life, such as parenting and parent-child relationships are more salient predictors of children's development than are distal markers such as family type or income (e.g. Dishion and Patterson 2006; Hill and Maughan 2001; Juby and Farrington 2001; Lansford 2009). However, in contrast to the abundance of data documenting change in family composition and income over time, next to nothing is known about whether and how parenting may have changed.

Successful parenting involves many complex skills and qualities, but two key dimensions are often highlighted (Barber et al. 2005; Baumrind 1991; Dishion and Patterson 2006; Hoeve et al. 2009; Steinberg and Silk 2002). First, aspects of parental control are important, including parental monitoring of out-of-home activities, parental expectations about children's conduct, clear limit-setting and rules, and the use of consistent and effective discipline. Evidence from longitudinal studies and randomized intervention trials, including analyses of mechanisms mediating intervention effects, suggests that active parental monitoring may have a causal influence on adolescent problem behavior (Dishion and Patterson 2006; Hoeve et al. 2009; Farrington 1995; Patterson et al. 1992). Furthermore, parents of boys at high risk for anti-social behavior in middle childhood have been reported to reduce their levels of supervision and guidance as their children reach adolescence. This early 'parental disengagement', although partly driven by youth behavior change, further increases risks for adolescent problem behavior (Dishion et al. 2004a). In addition, it is clear that child disclosure is critical for parental monitoring to be effective, especially of adolescents' out-of-home activities (Stattin and Kerr 2000). More generally, constructive forms of parental discipline are linked to lower levels of problem behavior in children and adolescents, including clarity of expectations, consistent use of incentives and consequences (Patterson et al. 1992) and proactive use of discipline (Gardner et al. 1999; Pettit et al. 1997). These strategies form a major focus of effective parenting interventions to reduce adolescent problem behavior (Woolfenden et al. 2001). Studies have also found that levels of parental control vary by family type, with lower levels of monitoring in lone parent households (Astone and McLanahan 1991), and step families (Kim et al. 1999). Social attitude surveys in the US and the UK show a systematic shift in parenting values over time, with a long-term change from valuing obedience to valuing autonomy (Alwin 2001; Smith and Farrington 2004). An important question, then, is whether historical shifts in values, as well as in family structure, have been accompanied by changes in parenting behavior, such as reduced supervision, or lowered parental expectations.

Positive involvement including parental interest, warmth, and time spent in joint activities is a second key aspect of the parent-child relationship related to youth adjustment (Hipwell et al. 2008; Patterson et al. 1992; Steinberg and Silk 2002), and encouraging positive and responsive parenting is also an important target and mediator of change in successful interventions (Dishion et al. 2008; Dishion and Kavanagh 2003; Gardner et al. 2006). Again, little is known about whether and how the quality of the parent-child relationship has changed against a background of marked social changes in family composition and increased parental work pressures.

One direct cohort comparison of parenting and family relationships focused on Scottish teenagers assessed in 1987 or in 2006. The study found on the one hand that adolescent worries about family relationships had increased, as had arguments with parents, but that young 
people also reported more time on family outings (Sweeting et al. 2010). However, items measuring family relationships were not identical, and this might also explain differences in scores across cohorts. Other indirect evidence comes from family time use studies. Repeated surveys from the US (Sayer et al. 2004), the UK (Fisher et al. 1999), and other countries (Gauthier et al. 2004) concur that there are broadly similar trends towards increasing parental time spent with children from the 1960 s to 2000 . However, time use studies lack detailed information about the type, quality or extent of parental involvement, and generally lack a developmental perspective, even providing insufficient information about the ages of children within each family. No study to our knowledge has tested whether parental control and expectations have changed over time. As a result, further research focused specifically on changes in parenting of adolescents is needed before drawing conclusions about links with trends in youth antisocial behavior. Thus, the first aim of this study was to examine whether parental control and involvement have changed over time.

A second important question is whether trends in parenting vary by socio-demographic group. Parenting is strongly influenced by the broader social and family context within which it occurs, and there is evidence that it may be impaired under conditions of increased environmental stress (e.g. Conger et al. 1994; Costello et al. 2003). Collishaw et al. (2007) found that not only did the proportions of single-parent and reconstituted families increase in UK cohorts between the mid-1970s and the late 1990s, but that economic disparities between family types increased sharply at the same time. As a result, single parent households (more likely to face income poverty even in the first cohort), became markedly more economically disadvantaged relative to two-parent families over time. Increasing 'polarization' between family types in economic terms raises the possibility that parenting may also have become more polarized, with economic and other stressors faced by lone parent families leading to a widening gap in the quality of parenting provided to young people. Thus, a second aim of the study was to examine the extent to which family and social variations in parenting have changed over time.

Previous research also highlights a number of differences in the way boys and girls are parented, especially during adolescence. For example, parents monitor adolescent girls more closely than boys (Stattin and Kerr 2000), and the quality of parents' interactions with sons and daughters also differs (Leaper et al. 1998). Given that these gender differences in parenting vary across cultural settings (Raley and Bianchi 2006) and are suggested to be influenced by parental gender roles in the home and the workplace (e.g. Hagan et al. 1985), they may also vary by historical period.
Thus a third aim was to test whether any changes in parenting have affected boys and girls in the same or different ways. Greater parental control and parent-child bonding for girls have been suggested to be linked to sex differences in conduct problems and delinquency (e.g. Hagan et al. 1985; Worthen 2011). A related issue then is whether any changes in gender-specific parenting of adolescents may in turn have affected gender-differences in adolescent conduct problems.

Studies of time trends are methodologically complex and difficult to undertake (Collishaw et al. 2004; Rutter and Smith 1995). Drawing robust and reliable conclusions hinges on the use of comparable measurement across repeat population samples. Existing surveys from different historical periods rarely contain the same measures of parenting or parent-child relationships. Purposive replications building on past epidemiological samples are therefore required. Furthermore, understanding connections between trends in parenting and youth conduct problems requires linked data on repeat cohorts of parents and adolescents. To our knowledge this is the first study with the requisite design and data to allow a test of the hypothesis that changes in parenting or parent-child relationships account for trends in youth conduct problems. This is the final aim of the study.

The current paper presents results from a study assessing secular change in adolescent experience and mental health in the UK over a twenty-year period-1986 and 2006 (Youth Trends; Collishaw et al. 2010). The study compared two national cohorts of teenagers and their parents using identical measures of parent-reported conduct problems and youth-reported parenting and parent-child relationships. In this way, the four study aims are addressed: (a) Has the quality of parenting or parent-child relationships changed between 1986 and 2006 for adolescents in the UK? (b) Do parenting and parent-child relationships vary by family type and social disadvantage? If so, have 'social inequalities' in parenting changed over time? (c) Are there differences in the parenting of adolescent boys and girls, and if so, have gender differences changed over time? (d) Are changes in adolescent conduct problems seen across these cohorts? If so, do changes in parenting or parentchild relationships account for any change in youth conduct problems?

\section{Methods}

\section{Study Samples}

Sample 1-1986 The 1970 British Cohort Study (BCS70, Goodman and Butler 1999) is an ongoing, prospective study of all children born in Great Britain in 1 week in 1970 $(N=17,160)$, assessed at regular intervals from birth, 
through childhood, adolescence and into adulthood. Accounting for deaths and emigrations the UK-wide target sample at age 16 in 1986 was $N=16,750$. We focused on study members living in England at the age 16 follow-up (estimated $N=14,076$; observed sample $N=9,766$ ) to allow direct comparison with the 2006 survey (see below). Young people completed questionnaires at home and/or at school $(N=4,524$ with data on parenting, $M$ age $=16.46$ years, $S D=$ 0.47 ), whilst parents were interviewed and completed questionnaires at home ( $N=7,120 ; 92 \%$ mothers). The reason for the lower response from adolescents than parents is that a teachers' strike affected school-based tracing of study members and in particular completion of youth questionnaires. Data collection took place between April 1986 and June 1987.

Sample 2-2006 The Health Surveys for England (HSE, Department of Health 2003) cover nationally representative cross-sections of private households in England. Together, the 2002 and 2003 surveys included 1,401 children born 1st April 1988 to 31st March 1990. All but three families gave consent in the original survey to be re-contacted at a later date. Questionnaires were sent to 1,398 young people and their parents together with study information sheets between March and May 2006. Questionnaires included the same instruments as used in BCS70. Return of completed questionnaires was taken to imply consent. Ethical approval for the study was obtained from the Institute of Psychiatry Ethical Committee (Research). 716 adolescents $(M$ age $=17.07$ years, $S D=0.57)$ and 734 carers (86\% mothers) responded to the 2006 survey (total observed sample, $N=747$ ).

Sample Representativeness and Participant Nonresponse Both samples were drawn from follow-ups of nationally representative samples (a complete birth cohort in the case of BCS70 and a cross-section of private households in the case of the HSE). Participant attrition is typical in longitudinal studies of this kind, but such studies also have the advantage of being able to use prior data on the full original cohorts to model and correct sources of bias (Wadsworth et al. 2003). Prior information about the samples collected at birth and at ages 5 and 10 years for BCS70 and at ages 11-14 years for HSE2006 was used to compare the characteristics of respondents and nonrespondents (Collishaw et al. 2010). Non-response in both studies was moderately higher among boys, ethnic minority groups, non-intact families, rented households, lower social class families, and was also higher among adolescents with prior physical health problems, low cognitive ability or who had high parent and teacher reported childhood conduct problem scores (supplementary Tables 1 and 2). Nonresponse weights were estimated separately for each study using predicted values derived from logistic regression analyses of prior predictors on age 16 response (including region, family social disadvantage, family type, child cognitive ability, and prior behavioral problems). Weight construction was completed prior to analysis of trends in parenting. Weights corrected known response biases associated with these prior measures (supplementary Tables 1 and 2).

\section{Measures}

Parenting and Parent-Child Relationships (YouthReported) The adolescent survey for the BCS70 cohort (1986) included a range of bespoke measures of adolescent experience, designed by Professor Neville Butler, with advice from experts in relevant fields (Goodman and Butler 1999). Measures of parenting and parent-child relationships were selected for inclusion in the 2006 replication
Table 1 Household demographics by year of study

${ }^{\text {a }}$ OR $[95 \% \mathrm{CI}]=$ Odds ratio with $95 \%$ confidence intervals $* * * p<0.001$

\begin{tabular}{lccc}
\hline & BCS70(1986)\% & HSE06 $(2006) \%$ & OR [95\% CI $]^{\mathrm{a}}$ \\
\hline Child gender (male) & 51.5 & 50.5 & $0.96[0.81,1.14]$ \\
Ethnic minority & 5.6 & 14.8 & $3.01[2.18,4.16]$ \\
Family type & & & \\
Intact & 76.9 & 61.8 & 1.0 \\
Single parent & 11.8 & 22.6 & $2.38[1.89,2.99]^{* * *}$ \\
Step family & 11.3 & 15.7 & $1.73[1.33,2.24]^{* * *}$ \\
Social disadvantage & & & \\
Maternal education (none/low) & 33.2 & 14.9 & $0.35[0.27,0.46]^{* * *}$ \\
Neither parent employed & 14.5 & 13.5 & $0.92[0.68,1.24]$ \\
Rented housing & 25.7 & 25.5 & $0.99[0.79,1.24]$ \\
Financial hardship (past year) & 15.9 & 25.7 & $1.83[1.47,2.27]^{* * *}$ \\
Multiple disadvantage (2+ above) & 33.7 & 34.9 & $1.05[0.87,1.28]$ \\
\hline
\end{tabular}


Table 2 Trends in parent expectations, monitoring and youth disclosure (youth reports)

${ }^{a}$ Parent expectations: percent endorsed as true; comparisons using logistic regression (true vs. false for each item)

${ }^{\mathrm{b}}$ Parent monitoring and youth disclosure: percent endorsed as mostly or almost always shown; comparisons using ordinal logistic regression (almost always, mostly, sometimes, hardly ever) OR/POR $[95 \% \mathrm{CI}]=$ Odds ratio or proportional odds ratio with $95 \%$ confidence intervals

$* p<0.05, * * p<0.01, * * * p<$ 0.001

\begin{tabular}{llll}
\hline & $1986 \%$ & $2006 \%$ & OR/POR [95\% CI \\
\hline Parental expectations $^{\mathrm{a}}$ & & & \\
Go to school & 93.1 & 96.9 & $2.17[1.15,4.10]^{*}$ \\
Do homework & 89.8 & 94.9 & $2.08[1.25,3.46]^{* *}$ \\
Help in the house & 94.8 & 95.6 & $1.19[0.75,1.90]$ \\
Be polite to parents & 74.9 & 86.3 & $2.13[1.60,2.84]^{* * *}$ \\
Tell parents time coming home & 82.7 & 88.2 & $1.51[1.14,1.99]^{* *}$ \\
Tell parents where going & 85.6 & 93.2 & $2.09[1.48,2.95]^{* * *}$ \\
Tell parents who going out with & 74.3 & 88.2 & $2.50[1.90,3.31]^{* * *}$ \\
Tell parents if in trouble & 88.1 & 97.5 & $5.57[3.30,9.39]^{* * *}$ \\
Parental monitoring & & & \\
Asks young person who with & & 78.0 & $1.51[1.27,1.82]^{* * *}$ \\
Asks young person where going & 67.0 & 87.1 & $1.61[1.31,1.97]^{* * *}$ \\
Asks young person what will do & 78.2 & 65.7 & $1.94[1.64,2.30]^{* * *}$ \\
Youth disclosure & 47.4 & & \\
Tells parent who with & & 85.5 & $1.32[1.08,1.62]^{* *}$ \\
Tells parent where going & 78.4 & 82.8 & $1.38[1.13,1.68]^{* *}$ \\
Tells parent what will do & 77.0 & 75.8 & $1.73[1.44,2.09]^{* * *}$ \\
\hline
\end{tabular}

study on the basis of preliminary analyses of the 1986 cohort assessing concurrent and predictive associations with age 16 conduct problems and adult criminal convictions (assessed at age 30). All measures of parental control and responsiveness used here were associated with reduced probability of multiple symptoms of conduct disorder (controlling for child gender, family type, social disadvantage, and ethnic group; supplementary Table 3). Several measures (e.g. parental monitoring, parent-child quality time) were also associated with reduced probability of adult criminal convictions (controlling for age 16 demographic factors and age 16 conduct symptoms).
Parental Expectations Eight items assessed parent expectations about youth behavior, e.g. "My parents expect me to help in the house when asked" (see Table 2). Adolescents endorsed each item as either true or false. An expectation score was created by summing the number of 'true' responses (alpha 1986 $=0.61,2006=0.62$ ).

Parental Monitoring of Out-of-Home Activities Parental monitoring was assessed using three items: "When you go out with friends your own age, how often do your parents ask you (a) who you are going to be with?; (b) where you are going?; (c) what you are going to be doing?". Response

Table 3 Youth reports of parent-child relationships and family cohesion

\begin{tabular}{llll}
\hline & $1986 \%$ & $2006 \%$ & OR/POR [95\% CI] \\
\hline Parents interested in child's ideas $^{\mathrm{a}}$ & 67.7 & 64.9 & $0.88[0.69,1.13]$ \\
Cares a lot what mother thinks $^{\mathrm{b}}$ & 72.5 & 71.3 & $0.95[0.76,1.18]$ \\
Cares a lot what father thinks $^{\mathrm{b}}$ & 65.3 & 58.2 & $0.72[0.58,0.88]^{* *}$ \\
Regular family meals $^{\mathrm{c}}$ & 83.3 & 71.2 & $0.50[0.39,0.63]^{* *}$ \\
Regular quality time spent with mother $^{\mathrm{d}}$ & 58.2 & 68.1 & $1.48[1.24,1.77]^{* *}$ \\
Regular quality time spent with father $^{\mathrm{d}}$ & 43.7 & 48.9 & $1.24[1.03,1.49]^{*}$ \\
\hline
\end{tabular}

a Parental interest: percent endorsed as yes; comparisons using logistic regression ('yes' vs. 'no' or 'don't know')

${ }^{b}$ Feelings about parents: percent endorsed as 'I care a lot'; comparisons using ordinal logistic regression ('I care a lot', 'I care a little', 'I don't care at all')

${ }^{\mathrm{c}}$ Family meals: percent endorsed as more than once a week; comparisons using ordinal logistic regression ('more than once a week', 'once a week', 'less than once a week', 'rarely/never')

${ }^{\mathrm{d}}$ Quality time: percent endorsed as most days or some days a week; comparisons using ordinal logistic regression ('most days a week', 'some days a week', 'once a week', 'occasionally', 'little or never')

OR/POR $[95 \% \mathrm{CI}]=$ Odds ratio or proportional odds ratio with $95 \%$ confidence intervals

$* p<0.05, * * p<0.01$ 
categories were 'almost always', 'mostly', 'sometimes', or 'hardly ever'. A monitoring score (alpha 1986 $=0.84$, $2006=0.87$ ) was created by summing across the three items (each coded 3 through to 0 ).

Youth Disclosure About Out-of-Home Activities Parallel questions assessed youth disclosure: "When you go out with friends your own age, how often do you tell your parents, (a) who you are really going to be with?; (b) where you are really going?; (c) what you are really going to be doing?". Response categories were the same as above. Item scores were summed to create a youth disclosure score (alpha 1986 $=0.89,2006=0.90$ ).

Parental Interest Youth were asked "Do you think your parents usually like to hear about your ideas?" (yes vs. no/ don't know).

Feelings About Parents Separate questionnaire items asked whether adolescents cared what their mother and their father thought of them ('I care a lot', 'I care a little', 'I don't care at all').

Joint Family Meals Youth were asked how often they sat down to eat a meal at home with their parents (more than once a week, once a week, less often, rarely/never).

Parent-Child Quality Time Separate questions asked adolescents to report how often they spent time with their mother and with their father "talking together, doing things together, going out together because you want to" (coded most days a week, some days a week, once a week, occasionally, little or never).

Demographic Information (Parent-Reported) Information was collected about child gender and age, ethnicity, family type, parental employment, parent-reported financial hardship, housing tenure, and parental education (degree or equivalent; GCSE grades A-C or better school leavingequivalent to US high school diploma grade 12; lower school leaving or none). Families were categorized as intact if the teenager lived with both biological parents and otherwise as single or step-parent households as appropriate. A composite rating of family SES was coded as follows: (a) very advantaged (parents educated to degree level, parent(s) in employment, owner-occupied housing, no reported financial hardship); (b) advantaged (parents have average or above school-leaving qualifications, parent(s) employed, owner-occupied housing, no reported financial hardship); (c) intermediate (at least one indicator of disadvantage present: below average parent qualifications, neither parent employed, rented accommodation, parentreported severe financial hardship over past 12 months); (d) disadvantaged (two or more indicators of social disadvantage). The demographic profile of the two samples is described in Table 1.

Youth Conduct Problems (Parent Reported) Parents completed the well-validated Rutter A scale (Rutter et al. 1970; Elander and Rutter 1996). Items were rated as 0 'does not apply', 1 'applies somewhat', 2 'certainly applies'. Six items were combined into a scale assessing conduct problems (vandalism, theft, disobedience, lies, bullies others, frequent fighting), with scores ranging from 0 to 12 (alpha $1986=0.77,2006=0.80)$.

\section{Analytic Strategy}

Analyses were undertaken in Stata 9 (StataCorp 2005). Proportional-odds ordinal logistic regression analyses were used to analyze ordinal scale scores and items. Results are described using proportional odds ratios (POR) and 95\% confidence intervals (CI). A proportional odds ratio can be interpreted as the increase in the odds of crossing any particular threshold on the outcome scale for a unit increase in the predictor. For the sake of brevity associated descriptive data in tables is presented using dichotomised variables. Logistic regression was used to analyze a small set of items with binary outcomes (individual parental expectations items and parental interest). The small difference in mean age of the two samples was controlled by including age (in months) as a covariate in all analyses. Reported means and percentages were adjusted to a "reference" age of 16.5 years. Analyses first tested differences in parenting by year of study, gender, family type (with dummy variables comparing single with intact and step with intact families), social disadvantage, and interactions between year of study and these other variables. The numbers of children from individual ethnic minority groups was too low to provide sufficient power for undertaking analyses by ethnicity. However, to assess if findings reflected changes in ethnic composition of the two samples, analyses were repeated for "White British" children only. Findings were closely comparable (available on request). Next, analyses tested differences in rates of parent-rated conduct problem between the 1986 and 2006 samples. The final step was to assess the impact of controlling for cohort change in parenting on trends in conduct problems. The comparison of unadjusted and adjusted estimates provides an indication of the contribution of parenting change. If conduct problems have increased and the adjusted estimate of cohort change is reduced when controlling for changes in parenting, then this would suggest that parenting change has contributed to the increase in adolescent conduct problems. Alternatively, 
if the adjusted estimate of cohort change in conduct problems is increased, this would provide evidence for a suppression effect whereby improvement in the quality of parenting has limited the extent of conduct problem trends. All analyses included non-response weights. Analyses of links between trends in parent-rated conduct problems and youth reported parenting used a multiple imputation approach (using the MICE system of chained equations in Stata, Royston 2009) in order to allow for partially missing data when combining across different measures and informants.

\section{Results}

Household Demographics

The composition of families in 1986 and 2006 differed in a number of ways (see Table 1). As expected, there were more single and step-parent households in 2006. More parents reported that the family had been seriously troubled by financial hardship in the past 12 months, but at the same time maternal school-leaving qualifications improved. There was no change in the proportion of families in rented accommodation or with no working parent. Around a third of families in each sample were defined as multiply disadvantaged. The proportion of families from an ethnic minority background increased from 6\% in 1986 to $15 \%$ in 2006.

To assess the representativeness of the retained samples, we also compared the weighted demographic profiles of the two samples with two other nationally representative samples of similarly aged adolescents-the 1985-1987 Youth Cohort Study (YCS, $N=8,064,16-17$ years, England and Wales; Courtenay 1988) and the 2004 British Child and Adolescent Mental Health Survey (BCAMHS, $N=1,151$, 15-16 year-old English sample, Green et al. 2005). The 1986 sample had a similar demographic profile to the YCS (male gender-1986 51.5\%, YCS 50.9\%; single parent$198611.8 \%$, YCS 14.5\%; neither parent employed-1986 $14.5 \%$, YCS $14.0 \%$; rented housing -1986 25.7\%, YCS $31.4 \%$ ) and the 2006 sample had a similar demographic profile to that of BCAMHS (male gender-2006 50.5\%, BCAMHS 50.9\%; single parent-2006 22.6\%, BCAMHS $25.5 \%$; neither parent employed-2006 13.5\%, BCAMHS $13.3 \%$; rented housing -2006 25.7\%, BCAMHS 27.5\%; ethnic minority—2006 14.8\%, BCAMHS 14.1\%).

Has Parenting of Adolescents Changed Between 1986 and 2006 ?

Tables 2 and 3 summarize cohort changes for measures of parental control (Table 2) and parental responsiveness
(Table 3). Summary data using binary indicators is accompanied by ordinal logistic regression utilizing full scale information.

As shown in Table 2, young people reported higher levels of parental expectations, higher levels of parental monitoring of their out of home activities, and higher levels of disclosure to parents about such activities, in 2006 than in 1986. Composite scale scores for parental expectations $(\mathrm{POR}=2.65[2.16,3.25], p<0.001)$, parental monitoring $(\mathrm{POR}=1.79[1.50,2.13], p<0.001)$, and youth disclosure $(\mathrm{POR}=1.57[1.30,1.90], p<0.001)$ were also higher in 2006 than in 1986.

Turning to measures of parent-child responsiveness (see Table 3), ratings of parental interest and feelings about mothers did not change over time, with the majority in each cohort saying that their parents were interested in their ideas and that they cared a lot what their mother thought of them. However, fewer young people in 2006 said they cared a lot what their father thought of them. Regular home family meals became less frequent, but the amount of youth-rated quality time spent with both mothers and fathers increased between 1986 and 2006.

Is There Evidence of Increasing or Decreasing Social 'Inequalities' in Parenting Between Different Family Type and Socio-Economic Groups?

Young people in non-intact or socially disadvantaged families on average reported lower parental control (expectations, monitoring, self disclosure) and responsiveness (lower parental interest, joint activities, quality time; Table 4). We then assessed whether social inequalities in parenting have changed over time by testing interactions between year of study and the socio-demographic factors in predicting parenting variables.

There was no evidence for any change between cohorts in associations between family type or SES and parental expectations (all interactions, $p>0.1$ ). However, significant interactions between year of study and social disadvantage suggested that increases over time in parent monitoring (interaction $\mathrm{POR}=1.32[1.13,1.55], p=0.001$ ) and youth disclosure (interaction $\mathrm{POR}=1.27$ [1.07, 1.49], $p=0.005$ ) were most pronounced for disadvantaged families (Fig. 1). There was a substantial social gradient in parental monitoring in $1986(\mathrm{POR}=0.72[0.68,0.77], p<0.001)$, but not in $2006(\mathrm{POR}=0.96[0.83,1.11], p=0.55)$, suggesting that high and low SES parents have become more 'equal' over time with respect to levels of parent monitoring.

Differences in parental interest by social status also reduced between 1986 and 2006 (year by social disadvantage interaction: $\mathrm{OR}=1.29$ [1.07, 1.57], $p=0.009$ ). Again, follow-up analyses confirmed that there was a substantial 
Table 4 Associations of parenting variables with family type, social disadvantage and child gender (1986 and 2006 samples combined)

\begin{tabular}{lllll}
\hline & $\begin{array}{l}\text { Single vs. intact } \\
\text { OR/POR }[95 \% \mathrm{CI}]\end{array}$ & $\begin{array}{l}\text { Step vs. intact } \\
\text { OR/POR }[95 \% \mathrm{CI}]\end{array}$ & $\begin{array}{l}\text { Social disadvantage } \\
\text { OR/POR }[95 \% \mathrm{CI}]\end{array}$ & $\begin{array}{l}\text { Girls vs. boys } \\
\text { OR/POR }[95 \% \mathrm{CI}]\end{array}$ \\
\hline $\begin{array}{llll}\text { Parental control } \\
\text { Parent expectations }\end{array}$ & $0.84[0.67,1.05]$ & $0.81[0.66,1.00]^{*}$ & $0.73[0.69,0.78]^{* * *}$ & $1.73[1.55,1.94]^{* * *}$ \\
Parent monitoring & $0.77[0.63,0.95]^{*}$ & $0.72[0.59,0.88]^{* *}$ & $0.76[0.72,0.81]^{* * *}$ & $2.02[1.81,2.24]^{* * *}$ \\
Youth disclosure & $0.80[0.65,0.98]^{*}$ & $0.76[0.61,0.94]^{*}$ & $0.78[0.73,0.82]^{* * *}$ & $1.80[1.62,2.01]^{* * *}$ \\
Parent-child responsiveness & & & & \\
Parent interest & $0.76[0.59,0.97]^{*}$ & $0.80[0.61,1.04]$ & $0.74[0.68,0.80]^{* * *}$ & $1.37[1.20,1.58]^{* * *}$ \\
Care mother thinks & $0.80[0.63,1.02]$ & $0.73[0.56,0.95]^{*}$ & $0.89[0.83,0.96]^{* *}$ & $1.86[1.62,2.12]^{* * *}$ \\
Care father thinks & $0.33[0.26,0.42]^{* * *}$ & $0.54[0.43,0.69]^{* * *}$ & $0.81[0.75,0.87]^{* * *}$ & $1.43[1.26,1.62]^{* * *}$ \\
Family meals & $0.87[0.65,1.16]$ & $0.63[0.48,0.84]^{* *}$ & $0.82[0.75,0.90]^{* * *}$ & $1.18[1.01,1.38]^{*}$ \\
Quality time (mum) & $0.70[0.56,0.87]^{* *}$ & $0.65[0.52,0.81]^{* * *}$ & $0.86[0.81,0.91]^{* * *}$ & $1.54[1.37,1.72]^{* * *}$ \\
Quality time (dad) & $0.21[0.16,0.28]^{* * *}$ & $0.43[0.34,0.54]^{* * *}$ & $0.78[0.73,0.83]^{* * *}$ & $0.80[0.71,0.90]^{* *}$ \\
\hline
\end{tabular}

Analyses used logistic regression for dichotomous parenting measures and ordinal logistic regression for ordinal scales. Interactions with year of study were tested and are described in the text where significant

OR/POR $[95 \% \mathrm{CI}]=$ Odds ratio or proportional odds ratio with $95 \%$ confidence intervals.

${ }^{*} p<0.05, * * p<0.01, * * * p<0.001$

social gradient in parental interest in $1986(\mathrm{OR}=0.69[0.63$, 0.76 ], $p=0.001)$, but not in 2006 (OR=0.91 [0.77, 1.08], $p=0.27$ ). Second, significant interactions indicated differences between step and intact families increased between 1986 and 2006 in relation to feelings about mothers (interaction $\mathrm{POR}=0.49[0.27,0.89], p=0.03$ ), and between single and intact families (interaction $\mathrm{POR}=0.47[0.26$, 0.85], $p=0.01$ ) and step and intact families (interaction $\mathrm{POR}=0.40[0.23,0.71], p=0.002)$ in relation to feelings about fathers. There was no difference between the two studies in young people's rating about fathers among those living in intact families, but a decline over time in ratings for lone parent and step families (Fig. 2).

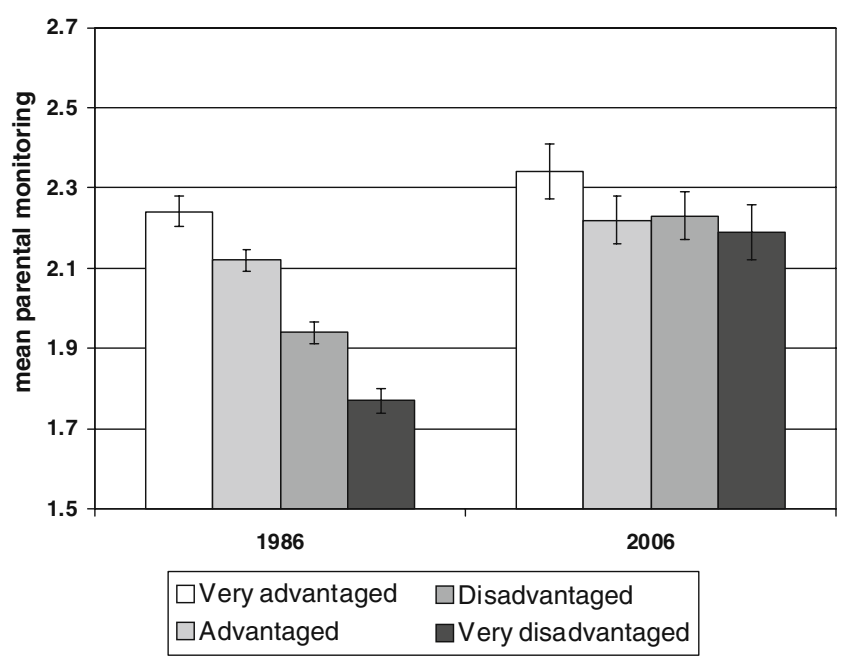

Fig. 1 Mean parental monitoring score by social disadvantage and year of study. Error bars represent standard errors
Are There Differences in Parenting of Adolescent Boys and Girls, and if So, Have Gender Differences Changed or Remained the Same Over Time?

All measures of parent-child control showed significant gender differences (Table 4). Girls reported higher parent expectations, monitoring, and self-disclosure of out-ofhome activities. There were no interactions with year of study $(p>0.1)$. Thus, gender differences in parental control did not change over time.

Girls also rated their parents as more interested, more often said they cared what their parents thought of them, more often had joint family meals and spent a greater amount of quality time with mothers. Boys reported spending more quality time with fathers than did girls (Table 4). Gender differences in parental interest narrowed between 1986 and 2006 (year by gender interaction: OR= $0.61[0.41,0.89], p=0.01)$, as did gender differences in

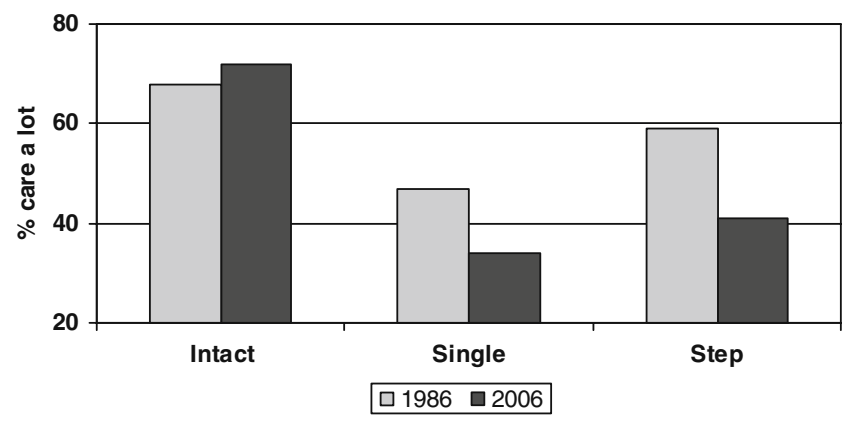

Fig. 2 Attitudes about fathers by year of study and family type. Proportion of young people who reported that they cared a lot what their father thought about them shown 
quality time with mothers (year by gender interaction: $\mathrm{OR}=$ $0.55[0.39,0.76], p<0.001)$. In particular, girls reported greater parental interest than boys in $1986(\mathrm{OR}=1.50[1.29$, 1.74], $p<0.001)$ but not in $2006(\mathrm{OR}=0.90$ [0.63, 1.28], $p>$ $0.5)$. Similarly, girls reported greater quality time with mothers in 1986 ( $\mathrm{POR}=1.69$ [1.50, 1.92], $p<0.001)$, but not in 2006 ( $\mathrm{POR}=0.92[0.68,1.25], p>0.6)$. Other interactions of year of study with gender were not significant $(p>0.2)$.

\section{Trends in Youth Conduct Problems}

Mean parent-reported conduct problems increased between 1986 and $2006(\mathrm{POR}=1.24$ [1.01, 1.52], $p=0.04)$. Separate analyses by gender showed a significant increase for girls (1986: mean $=0.85, \mathrm{SD}=1.63 ; 2006:$ mean $=1.15, \mathrm{SD}=$ 1.89; $\mathrm{POR}=1.36[1.01,1.83], p=0.03)$, but not for boys (1986: mean $=1.00, \mathrm{SD}=1.77 ; 2006:$ mean $=1.29, \mathrm{SD}=$ 2.28; $\mathrm{POR}=1.16[0.85,1.62], p=0.35)$. However, there was no significant interaction between gender and cohort, indicating no change in gender differences in conduct problems over time (cohort by gender interaction, $\mathrm{POR}=$ $0.83[0.55,1.25], p=0.37)$.

\section{Do Changes in Parenting Account for Changes in Youth} Conduct Problems?

To assess the estimated impact of changes in parenting on trends in youth conduct problems, step-wise multivariate ordinal logistic regression analyses compared year of study differences in youth conduct problem either unadjusted or adjusted for changes in family demographics, parenting and parent-child relationships (Table 5). The logic of these analyses is as follows. If changes in family demographics or parenting have contributed to increased rates of conduct problems in 2006 then when these factors are controlled the adjusted proportional odds ratio for cohort will be reduced (analogous to conventional tests of mediation). Alternatively, if the adjusted coefficient for the comparison between cohorts is increased this indicates a suppression effect. Analyses controlling for family type and social disadvantage showed a modest reduction in the cohort difference in conduct problems (model 2). In contrast, adjusted estimates of the cohort difference in conduct problems were by and large either greater or unchanged when accounting for changes in parenting (models $3 \mathrm{a}-3 \mathrm{~h}$ ). There was thus no evidence that the impact of secular change on adolescent conduct problems was mediated by change in quality of parenting. In fact, analyses suggested that the cohort increase in conduct problems might have been somewhat greater $(\mathrm{POR}=1.38$ vs. 1.24$)$ if parenting and parent-child relationships had remained unchanged over this period (i.e. a possible suppressor effect, model $4 \mathrm{a}$ ), whilst the final model
Table 5 Change in youth conduct problems (unadjusted and adjusted for change in parenting)

Covariates

Increased risk for conduct problems (2006 vs 1986) POR $[95 \% \mathrm{CI}]$

\begin{tabular}{ll} 
Model 1 (unadjusted) & $1.24[1.01-1.52]^{*}$ \\
Model 2 (adjusted, family type and SES) & $1.17[0.95-1.43]$ \\
Model 3 (adjusted, one covariate at a time) & \\
a. Monitoring & $1.36[1.10-1.67]^{* *}$ \\
b. Disclosure & $1.37[1.12-1.69]^{* *}$ \\
c. Expectations & $1.40[1.13-1.74]^{* *}$ \\
d. Parental interest & $1.24[1.01-1.52]^{*}$ \\
e. Care mother thinks & $1.24[1.01-1.52]^{*}$ \\
f. Care father thinks & $1.18[0.96-1.44]$ \\
g. Family meals & $1.17[0.95-1.44]$ \\
h. Quality time with parents & $1.35[1.10-1.65]^{* *}$ \\
Model 4 (fully adjusted) & \\
a. All parenting & $1.38[1.11-1.73]^{* *}$ \\
a. All parenting and socio-demographic & $1.30[1.05-1.62]^{*}$ \\
\hline
\end{tabular}

Dependent variable is adolescent conduct problems (range 0-12). POR $[95 \% \mathrm{CI}]=$ proportional odds ratio with $95 \%$ confidence intervals. POR refers to the unadjusted association between cohort and conduct problems (model 1), or the association between cohort and conduct problems controlled for family type and SES (model 2), controlled for each parenting measure individually (models $3 \mathrm{a}-3 \mathrm{~h}$ ), or controlled for all parenting (model $4 \mathrm{a}$ ) or all parenting and sociodemographic measures jointly (model 4b)

Multiple imputation used to ensure consistent sample Ns across models (1986, $N=9,766 ; 2006, N=747)$

${ }^{*} p<0.05,{ }^{* *} p<0.01$

controlling for all changes in family demographics and parenting continued to show a significant effect of cohort on youth conduct problems (POR=1.30 [1.05-1.62]).

\section{Discussion}

Parenting is an important influence on individual differences in problem behavior in young people and an effective target for intervention (Dishion and Patterson 2006; Gardner et al. 2006). Given the marked changes in family life that took place over past decades, it is important to consider whether and how parenting and parent-child relationships have changed, and what if any effect these changes have had on the prevalence of youth conduct problems. The present study is the first, to our knowledge, to empirically test these issues.

Has Parenting of Adolescents Changed, and if so How?

Longitudinal and intervention studies demonstrate that deficits in parental monitoring and control, and in respon- 
sive, involved parenting are likely causal influences on youth antisocial behavior (Dishion and McMahon 1998; Dishion and Kavanagh 2003; Farrington 1995; Hipwell et al. 2008; Hoeve et al. 2009; Patterson et al. 1992). Suggestions that the quality of parental control and positive parent-child relationships has declined (Ambert 2007) were not borne out in this study. Results indicated increases over time in parental monitoring, youth disclosure about out-ofhome activities, and parental expectations about good behavior. Adolescents rated their parents as just as interested in 2006 as in 1986. There was a reduction in joint family meals, but young people reported spending more quality time with their parents. The main trend that was not in a positive direction was that child-father relationships became more fractured for those in single or step-parent families.

The findings are broadly consistent with data from repeated time use surveys in the US, the UK and other countries indicating greater time spent by mothers and fathers in child care activities (Gauthier et al. 2004; Sayer et al. 2004). There are several possible explanations for the changes in parenting and parent-child relationships reported here. These include demographic change, time reallocation, and changes in parental norms and values (Gauthier et al. 2004). First, pressures due to increases in parental work time and changes in family type may have been offset by decreasing family size, and changes in parental attributes such as beginning a family at an older age following longer periods of post-school education. Second, evidence from time use surveys suggests that parents spend less time in adult leisure activities, personal care and sleep, thus compensating for an increase in maternal time in employment (Gauthier et al. 2004). Third, social norms may have changed, with parents now expecting to be more actively involved in child care activities, with greater encouragement for parents to read and play with younger children, and increased pressure to monitor older children's out of home behavior.

\section{Is There Evidence for Increasing Social Inequalities in Parenting?}

The second aim was to test the possibility that overall comparisons of past and present cohorts of families might mask an increase in parenting problems in some vulnerable subgroups of families. On the whole, results did not support a polarization of parenting. If anything, findings suggested a narrowing of the gap in parenting between socially advantaged and disadvantaged families. Marked social gradients in parental monitoring, youth disclosure and parental interest in 1986 had disappeared by 2006 . However, the study was based on national general population samples, and it remains uncertain whether this positive picture generalizes to more extreme groups of disadvantaged families in society.

Have Changes in Parenting Affected Girls and Boys Similarly?

It is well-established that there are important differences in parenting and parent-child relationships between girls and boys, particularly in adolescence. Consistent with previous research on gender differences in parenting (Raley and Bianchi 2006), girls reported higher parental expectations and monitoring, and these gender differences did not change over time. Girls also reported greater parental interest, communicated more about their out-of-home activities with their parents, cared more strongly about their parents' opinions of them and more often chose to spend time with their mothers than did boys. In contrast, boys reported greater quality time spent with fathers. Gender differences in some measures of parental responsiveness (parental interest, quality time with mothers) reduced between 1986 and 2006. Changes in adult gender roles, including increased maternal employment and increased paternal family involvement (Fisher et al. 1999; Gauthier et al. 2004) offer one possible explanation. The fact that gender differences with respect to measures of parental control remained as pronounced in 2006 as 1986 may reflect that parental concerns about adolescent girls' out-of-home safety remain undiminished.

Is There a Connection Between Trends in Parenting and Trends in Youth Conduct Problems?

The analyses reported here provide additional evidence of a long-term increase in youth conduct problems in the UK, in line with previous reports on other national cohorts (Collishaw et al. 2004, 2007; Rutter and Smith 1995). However, the increase observed here was smaller than for cohorts assessed between 1974 and 1999. Other recent evidence from the UK also suggests a leveling out or reversal of the increase in youth antisocial behavior over the last decade (Maughan et al. 2008).

The findings of this study do not support the view that a population-wide 'decline' in quality of parenting has led to an increase in youth antisocial behavior. As anticipated, lower levels of parental control and responsiveness were strongly associated with risk for conduct problems; longitudinal analyses for the first cohort also showed that they predicted future risk of adult crime (supplementary Table 3). However, as noted, quality of parenting appears if anything to have improved and these changes may have been protective. Models suggested that increases over time in conduct problems might have been greater had it not been for observed changes in parental control and responsive- 
ness. The cohort difference in conduct problems was reduced when controlling for change in family composition, but rates of conduct problems remained higher in 2006 when controlling for all measured changes in family composition, social disadvantage and parenting.

\section{How Far Do the Results Apply to Other Countries?}

It is not known whether similar changes in parental control and positive parenting have occurred in other countries. However, it is plausible that this may be the case, as time use surveys show similar rises in parental time spent with children across multiple Western countries (Gauthier et al. 2004). Nevertheless, it is important to note that parenting practices differ between different countries, and that cultural context and norms are important factors in determining how parenting influences children's outcomes (Furstenberg et al. 1999; Gershoff et al. 2010).

\section{Strengths and Limitations}

The study has many advantages, most importantly the availability of identical measures of parenting in two comparable national population samples of families assessed 20 years apart. At the same time, several limitations warrant consideration.

First, both studies were affected by non-response, with some selective loss of more disadvantaged families. However, we do not believe that attrition-related biases can account for the findings. Extensive efforts were made to account for selective non-response. Attrition weights adequately corrected the profile of both adolescent samples to be representative in terms of measures collected earlier in childhood (supplementary Tables 1 and 2; Collishaw et al. 2010), and we also used multiple imputation to take account of partial missing data at age 16 in the multivariate analyses. It remains possible that unmeasured adolescent factors might also have influenced probability of response. However, the demographic profiles of the two samples were comparable with those of other national data on adolescents at each time point. Furthermore, along with increased youth conduct problems, youth-reported emotional problems have also increased for the 2006 sample (Collishaw et al. 2010). It is hard to conceive how differences in selective retention can account for a picture of improvements in quality of parenting, but deterioration in youth mental health.

Second, only youth reports of parenting were available in this study. Although the addition of parent reports would have been welcome, research suggests that youth reports tally more closely with independent observers' reports of parental behavior (Gonzales et al. 1996). Youth reports are also likely to be less susceptible to social desirability biases that might affect parents' own responses (Hofferth 2004).

Finally, although many important facets of parenting were assessed, in-depth assessments were not available. As a result, although we know about the extent of reported parental expectations, monitoring and discipline, our measures did not directly address effectiveness of parental control. The parental expectations scale also had low internal consistency, possibly reflecting the diverse aspects of youth behavior addressed. Questions about quality and nature of parental involvement covered several important constructs (e.g. perceived parental interest, and time spent together), but no data was available on the quality of interactions or expression of affect between parents and adolescents (e.g. yelling, insulting, warmth, or laughter). There is a long history of work on measurement of these more dynamic aspects of parenting, using naturalistic observational techniques, family discussion tasks and semistructured interviews (e.g. Gardner 2000; Le Couteur and Gardner 2008). These costly methods are rarely used in large population cohorts, and therefore are likely to remain beyond the scope of cross-time epidemiological comparisons of the kind undertaken here. A more feasible goal for future research is to look at other broader indicators of family functioning where standardized assessments are commonly used, including family-level climate and communication patterns, parental discord and family social support (Emery 1982; Hill and Maughan 2001). Parenting might also be conceptualized more broadly than we have here to include parental risk behaviors (e.g. antisocial behavior and substance use) that influence the norms and role models provided within the family for young people (Dishion et al. 2004b).

\section{Implications}

Our study found little evidence of a decline in many aspects of parenting and parent-child relationships known to be most strongly linked with youth antisocial behavior. In fact, the results tended to suggest that in some respects the quality of parenting had improved (notably increases in parental expectations, monitoring and parent-child quality time). Changes in parenting as far as assessed in this study thus seem unlikely to account for trends in youth antisocial behavior over this period in the UK. It is worth reemphasizing that this does not mean that parenting is unimportant as far as youth antisocial outcomes are concerned. At an individual level there are strong associations between parenting and youth behavior, including in this study. As shown by the longitudinal analyses of the first cohort parenting also influences long-term risk for antisocial behaviour. However, it is well known that different factors can account for population level time trends, compared to those accounting for individual differences (Collishaw et al. 2007; Robinson 1950). To use an 
analogy, at an individual level height is highly heritable (Silventoinen et al. 2000), and the best predictor of a child's height is his or her parents' height; yet the average height in the population as a whole increased substantially during the 19th and 20th centuries, primarily due to changes in health and nutrition (Fredriks et al. 2000).

With respect to the connection between trends in parenting and conduct problems, one policy implication is that there is an important distinction between intervention targets that are amenable at the individual level and what may be most effective in reducing population prevalence in antisocial behaviour. A number of evidence-based targeted parenting interventions are effective at altering youth problem behavior trajectories (Hoeve et al. 2009; Woolfenden et al. 2001), underscoring the importance of parenting for understanding individual variation and individual change in conduct problems. At the population level it appears that changes in parenting have not resulted in any major change in conduct problems, although these data are consistent with the notion that improvements in aspects of parenting may have limited the rise in conduct problems.

Drawing firm conclusions about effective policies for reducing the prevalence of adolescent conduct problems will require better understanding of what explains betweenpopulation variability in youth adjustment. Further research is needed drawing not only on insights from studies of within-population individual differences, but that also considers social and cultural changes that have affected whole cohorts of young people (Eckersley 2006; Elder 1999; Crockett and Silbereisen 2000). For example, while parental monitoring may have increased, neighborhood monitoring (and other aspects of social cohesion) may have decreased in many places. More generally, a range of alternative explanations for trends in youth antisocial behavior require testing. Other evidence from this dataset suggests that whilst quality of parenting behavior has improved, parent mental health has significantly worsened over time, contributing to increases in youth emotional problems (Schepman et al. 2011). Evidence from repeat Scottish samples of adolescents also suggests that adolescent worries about family life and educational stress have contributed to increasing levels of emotional problems (West and Sweeting 2003; Sweeting et al. 2010). Other factors of potential importance may include changes in social and cultural norms, in influences from peers or via the media, or in the availability of drugs and alcohol.

\section{References}

Achenbach, T. M., Dumenci, L., \& Rescorla, L. A. (2003). Are American children's problems still getting worse? A 23-year comparison. Journal of Abnormal Child Psychology, 31, 1-11.
Alwin, D. (2001). Parental values, beliefs, and behavior: A review of the promulga for research in the new century. In T. Owens \& S. Hofferth (Eds.), Children at the Millenium: Where have we come from, where are we going? (pp. 97-139). Advances in Life Course Research Series. New York: Elsevier Science.

Amato, P. R., \& Booth, A. (2000). A generation at risk: Growing up in an era of family upheaval. Cambridge: Harvard University Press.

Ambert, A. (2007). Contemporary family trends. The rise in the number of children and adolescents who exhibit problem behaviors: Multiple causes. Ottawa: Vanier Institute of the Family.

Astone, N. M., \& McLanahan, S. (1991). Family structure, parental practices and high school completion. American Sociological Review, 56, 309-320.

Barber, B., Stolz, H., \& Olsen, J. (2005). Parental support, psychological control, and behavioral control: assessing relevance across time, culture, and method. Monographs of the Society for Research in Child Development, 70, 1-137.

Baumrind, D. (1991). The influence of parenting style on adolescent competence and substance use. The Journal of Early Adolescence, 11, 56-95.

Collishaw, S., Maughan, B., Goodman, R., \& Pickles, A. (2004). Time trends in adolescent mental health. Journal of Child Psychology \& Psychiatry, 45, 1350-1362.

Collishaw, S., Goodman, R., Pickles, A., \& Maughan, B. (2007). Modeling the contribution of changes in family life to time trends in adolescent conduct problems. Social Science \& Medicine, 65, 2576-2587.

Collishaw, S., Maughan, B., Natarajan, L., \& Pickles, A. (2010). Trends in adolescent emotional problems in England: a comparison of two national cohorts twenty years apart. Journal of Child Psychology \& Psychiatry, 51, 885-894.

Conger, R., Ge, X., Elder, G., Lorenz, F., \& Simons, R. (1994). Economic stress, coercive family process, and developmental problems of adolescents. Child Development, 65, 541-561.

Costello, E. J., Compton, S., Keeler, G., \& Angold, A. (2003). Relationships between poverty and psychopathology: a natural experiment. JAMA, 290, 2023-2029.

Courtenay, G. (1988) England and Wales Youth Cohort Study: Report on Cohort 1 Sweep 1. Research and Development Series no. 41, Youth Cohort Series no. 1, Sheffield: Manpower Services Commission.

Crockett, L. A., \& Silbereisen, R. K. (Eds.). (2000). Negotiating adolescence in times of social change. Cambridge: Cambridge University Press.

Department of Health. (2003). Health survey for England 2002. London: The Stationary Office.

Dishion, T. J., \& Kavanagh, K. (2003). Intervening in adolescent problem behavior: A family-centered approach. New York: Guilford.

Dishion, T. J., \& McMahon, R. (1998). Parental monitoring and prevention of child and adolescent problem behavior: a conceptual and empirical formulation. Clinical Child and Family Psychology Review, 1, 61-75.

Dishion, T. J., \& Patterson, G. R. (2006). The development and ecology of antisocial behavior in children and adolescents. In D. Cicchetti \& D. J. Cohen (Eds.), Developmental psychopathology: Risk, disorder, and adaptation (Vol. 3, pp. 503-541). New York: Wiley.

Dishion, T. J., Nelson, S., \& Bullock, B. (2004a). Premature adolescent autonomy: parent disengagement and deviant peer process in the amplification of problem behavior. Journal of Adolescence, 27, 515-530.

Dishion, T. J., Owen, L. D., \& Bullock, B. M. (2004b). Like father, like son: toward a developmental model for the transmission of 
male deviance across generations. The European Journal of Developmental Psychology, 1(2), 105-126.

Dishion, T. J., Shaw, D. S., Connell, A. M., Gardner, F., Weaver, C. M., \& Wilson, M. N. (2008). The family check-up with high-risk indigent families: preventing problem behavior by increasing parents' positive behavior support in early childhood. Child Development, 79, 1395-1414.

Eckersley, R. (2006). Is modern culture a health hazard? International Journal of Epidemiology, 35, 252-258.

Elander, J., \& Rutter, M. (1996). Use and development of the Rutter parents' and teachers' scales. International Journal of Methods in Psychiatric Research, 6, 63-78.

Elder, G. H. (1999). Social change in life experience. 25th Anniversary edition. Boulder: Westview.

Emery, R. E. (1982). Interparental conflict and the children of discord and divorce. Psychological Bulletin, 92, 310-330.

Farrington, D. (1995). The development of offending and antisocial behaviour from childhood: key findings from the Cambridge Study of Delinquent Development. Journal of Child Psychology \& Psychiatry, 36, 929-964.

Fisher, K., McCulloch, A., \& Gershuny, J. (1999). British fathers and children: A report for Channel 4 dispatches. Essex University: Institute for Social and Economic Research.

Fomby, P., \& Cherlin, A. J. (2007). Family instability and child wellbeing. American Sociological Review, 72, 181-204.

Fredriks, A. M., Van Buuren, S., Burgmeijer, R. J. F., Meulmeester, J. F., Beuker, R. J., Brugman, E., et al. (2000). Continuing positive secular growth change in the Netherlands 1955-1997. Pediatric Research, 47, 316-323.

Furstenberg, F. F., Cook, T. D., Eccles, J., Elder, G. H., Jr., \& Sameroff, A. (1999). Managing to make it: Urban families and adolescent success. Chicago: University of Chicago Press.

Gardner, F. (2000). Methodological issues in the use of observational methods for measuring parent child interaction. Clinical Child and Family Psychology Review, 3, 185-198.

Gardner, F., Sonuga-Barke, E., \& Sayal, K. (1999). Parents anticipating misbehaviour: an observational study of strategies parents use to prevent conflict with behaviour problem children. Journal of Child Psychology and Psychiatry, 40, 1185-1196.

Gardner, F., Burton, J., \& Klimes, I. (2006). Randomised controlled trial of a parenting intervention in the voluntary sector for reducing child conduct problems: outcomes and mechanisms of change. Journal of Child Psychology \& Psychiatry, 47, 1123-1132.

Gauthier, A. H., Smeeding, T. M., \& Furstenberg, F. (2004). Are parents investing less time in children? Trends in selected industrialized countries. Population and Development Review, 30, 647-671.

Gershoff, E. T., Grogan-Kaylor, A., Lansford, J. E., Chang, L., Zelli, A., Deater-Deckard, K., et al. (2010). Parent discipline practices in an international sample: associations with child behaviors and moderation by perceived normativeness. Child Development, 81 , 487-502.

Gonzales, N. A., Cauce, A. M., \& Mason, C. A. (1996). Interobserver agreement in the assessment of parental behavior and parent-adolescent conflict: African American mothers, daughters, and independent observers. Child Development, 67, 1483-1504.

Goodman, A., \& Butler, N. R. (1999). BCS70-The British Cohort Study: The 16-year follow-up. A guide to the BCS70 16 year data available at the economic and social research council data archive. London, UK: Social Statistics Research Unit, City University; not dated.

Gottfredson, M., \& Hirschi, T. (1990). A general theory of crime. Palo Alto: Stanford University Press.

Green, H., McGinnity, A., Meltzer, H., Ford, T., \& Goodman, R. (2005). Mental health of children and young people in Great Britain, 2004. Basingstoke: Palgrave Macmillan.
Hagan, J., Gillis, A., \& Simpson, J. (1985). The class structure of gender and delinquency: toward a power-control theory of common delinquent behavior. The American Journal of Sociology, 90, 1151-1178.

Halsey, A. H., \& Webb, J. (2000). 20th century British social trends. Basingstoke: Palgrave Macmillan.

Hill, J., \& Maughan, B. (2001). Conduct disorders in childhood and adolescence (pp. 507-552). Cambridge: Cambridge University Press.

Hipwell, A., Keenan, K., Kasza, K., Loeber, R., Stouthamer-Loeber, M., \& Bean, B. (2008). Reciprocal influences between girls' conduct problems and depression, and parental punishment and warmth: a six year prospective analysis. Journal of Abnormal Child Psychology, 36, 663-677.

Hoeve, M., Dubas, J. S., Eichelsheim, V. I., Van der Laan, P. H., Smeenk, W., \& Gerris, J. R. M. (2009). The relationship between parenting and delinquency: a meta-analysis. Journal of Abnormal Child Psychology, 37, 749-775.

Hofferth, S. L. (2004). Response bias in a popular indicator of reading to children. Sociological Methodology, 36, 301-315.

Hoynes, H. W., Page, M. E., \& Stevens, A. H. (2006). Poverty in America: trends and explanations. Journal of Economic Perspectives, 20, 47-68.

Juby, H., \& Farrington, D. P. (2001). Disentangling the link between disrupted families and delinquency. British Journal of Criminology, $41,22-40$.

Kim, J., Hetherington, E., \& Reiss, D. (1999). Associations among family relationships, antisocial peers, and adolescents' externalizing behaviors: gender and family type differences. Child Development, 70, 1209-1230.

Lansford, J. E. (2009). Parental divorce and children's adjustment. Perspectives on Psychological Science, 4, 140-152.

Leaper, C., Anderson, K. J., \& Sanders, P. (1998). Moderators of gender effects on parents' talk to their children: a meta analysis. Developmental Psychology, 34, 3-27.

Le Couteur, A., \& Gardner, F. (2008). Structured interviews and observations. In M. Rutter, D. Bishop, D. Pine, S. Scott, J. Stevenson, E. Taylor, \& A. Thapar (Eds.), Rutter's child and adolescent psychiatry (5th ed.). Oxford: Blackwell.

Maughan, B., Iervolino, A. C., \& Collishaw, S. (2005). Time trends in child and adolescent mental disorders. Current Opinion in Psychiatry, 18, 381-385.

Maughan, B., Collishaw, S., Meltzer, H., \& Goodman, R. (2008). Recent trends in UK child and adolescent mental health. Social Psychiatry and Psychiatric Epidemiology, 43, 305-310.

Patterson, G., Reid, J., \& Dishion, T. (1992). Antisocial boys. Eugene: Castalia.

Pettit, G. S., Bates, J. E., \& Dodge, K. A. (1997). Supportive parenting, ecological context, and children's adjustment: a seven-year longitudinal study. Child Development, 68, 908923.

Raley, S., \& Bianchi, S. (2006). Sons, daughters, and family processes: does gender of children matter? Annual Review of Sociology, 32, 401-421.

Robinson, W. S. (1950). Ecological correlations and the behavior of individuals. American Sociological Review, 15, 351-357.

Royston, P. (2009). Multiple imputation of missing values: further update of ice, with an emphasis on categorical variables. Stata Journal, 9, 466-477.

Rutter, M., \& Smith, D. J. (1995). Psychosocial disorders in young people: Time trends and their causes. Chichester: Wiley.

Rutter, M., Tizard, J., \& Whitmore, K. (1970). Education, health and behaviour. London: Longman.

Sayer, L., Gauthier, A., \& Furstenberg, F. (2004). Educational differences in parents' time with children: cross-national variations. Journal of Marriage \& the Family, 66, 1152-1169. 
Schepman, K., Collishaw, S. Gardner, F., Maughan, B., Scott, J., \& Pickles, A. (2011). Do changes in parent emotional problems explain time trends in adolescent emotional problems? Social Science and Medicine. 73, 293-300

Scott, J., Treas, J., \& Richards, M. (2004). Blackwell companion to the sociology of families. New York: Blackwell.

Silventoinen, K., Kaprio, J., Lahelma, E., \& Koskenvuo, M. (2000). Relative effects of genetic and environmental factors on body height: differences across birth cohorts among Finnish men and women. American Journal of Public Health, 90, 627-630.

Smith, C., \& Farrington, D. (2004). Continuities in antisocial behavior and parenting across three generations. Journal of Child Psychology \& Psychiatry, 45, 230-248.

StataCorp. (2005). Stata statistical software: Release 9.0. College Station: Stata.

Stattin, H., \& Kerr, M. (2000). Parental monitoring: a reinterpretation. Child Development, 71, 1072-1085.

Steinberg, L., \& Silk, J. (2002). Parenting adolescents. In M. J. Bornstein (Ed.), Handbook of parenting: Children and parenting (2nd ed., Vol. 1, pp. 103-134). Mahwah: Lawrence Erlbaum Associates.
Sweeting, H., West, P., Young, R., \& Der, G. (2010). Can we explain increases in young people's psychological distress over time? Social Science and Medicine, 71, 1819-1830.

Wadsworth, M. E., Butterworth, S. L., Hardy, R. J., Kuh, D. J., Richards, M., Langenberg, C., et al. (2003). The life course prospective design: an example of benefits and problems associated with study longevity. Social Science and Medicine, 57, 2193-2205.

Wardle, L. D. (2007). The fall of marital stability and the rise in juvenile delinquency. Journal of Law and Family Studies, 10, 83-110.

West, P., \& Sweeting, H. (2003). Fifteen, female and stressed: changing patterns of psychological distress over time. Journal of Child Psychology and Psychiatry, 44, 399-411.

Woolfenden, S. R., Williams, K., \& Peat, J. (2001). Family and parenting interventions in children and adolescents with conduct disorder and delinquency aged 10-17. Cochrane Database of Systematic Reviews 2001, Issue 2. Art. No: CD003015. www. mrw.interscience.wiley.com/cochrane/clsysrev/articles/ CD003015/frame.html.

Worthen, M. G. F. (2011). Gender differences in parent-child bonding: implications for understanding the gender gap in delinquency. Journal of Crime and Justice, 34, 3-23. 